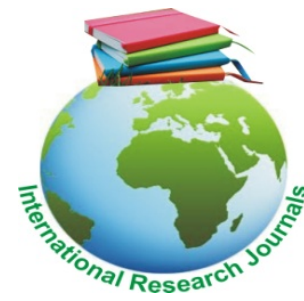

\title{
Health problems of child hawkers in Uyo, South-South Nigeria
}

\author{
*Johnson Ofonime E, and Ihesie Chukwuemeka A \\ Department of Community Health, University of Uyo Teaching Hospital, Uyo, Nigeria \\ ${ }^{*}$ Corresponding author's email: drjohnsonoe@yahoo.com
}

\begin{abstract}
Hawking among children is a common sight in most cities in Nigeria. The objective of this study was to determine possible health problems of children hawking in Uyo, southern Nigeria. This was a cross sectional study carried out among children selling along major traffic light intersections in Uyo metropolis. The instrument of data collection was a semi-structured questionnaire. Data was analyzed using SPSS version 20. A total of 225 hawkers participated in the study with a male: female ratio of 1.12:1 and a mean age of 13.27 ( \pm 2.52$)$ years. Most, 201 (89.3\%) worked for 4-7 days weekly and 88 (39.1\%) worked all day. Up to 54 (24.0\%) spent $9-13$ hours daily hawking. More than half, $135(58.5 \%)$ of them perceived hawking as dangerous. Sixty nine (30.7\%) had been involved in road traffic accident. Significantly more females $33(31.1 \%)$ than males $10(8.4 \%)$ reported ever experiencing sexual harassment or rape $(p<0.001)$. Headaches, $46(20.4 \%)$, general body pains, $40(17.7 \%)$ and leg pains, 36 (16.0\%) were the most frequently experienced health problems among the respondents. Other problems included fever, 24 (10.6\%) and tiredness/weakness, 34 (15.1\%). One case of pregnancy was reported. Awareness campaigns should be carried out in media outfits to discourage parents from exposing their children to such health problems.
\end{abstract}

Key words: Health problems, hawkers, accidents, sexual harassment, awareness campaigns.

\section{INTRODUCTION}

Street hawking is a common form of child labour in most cities in Nigeria as well as other developing countries (Okafor, 2010). The International Labour Organization (ILO) describes hazardous child labour as 'work which by its nature or the circumstances in which it is carried out, is likely to harm the health, safety or morals of children' (ILO, 2015). About 28.7 million children, $10.4 \%$ of children population in sub Saharan Africa are in hazardous labour (ILO, 2013). Hawkers' population has been reported to be dominated by under-aged children (Ayodele and Olubayo-Fatiregun, 2014). In addition to various socio-cultural and educational challenges, street hawking poses numerous health problems on children.

The commonest hazard associated with street hawking is physical injury. Risky behaviors like chasing buyers in moving vehicles, selling in-between moving vehicular traffic and street fighting increase the potential of harm resulting from accidents (Ayodele and OlubayoFatiregun, 2014; Okafor, 2010). The lack of supervision by adults further increases these risks. Hawking of petroleum products has also been associated with children and was reported as a significant contributor to the incidence of childhood burns in Northern Nigeria (Gali et al., 2004).

Sexual abuse is another common occurrence that threatens the health of children involved in hawking. Although incidences have been reported among the males, it is far commoner among the females. Key findings from a study in south eastern Nigeria identified sexual abuse as a major hazard among female hawkers. In the study, $69.9 \%$ of the respondents had been sexually abused with approximately $17 \%$ reporting penetrative sexual intercourse and the rest inappropriate touches (Ikechebelu et al., 2008). Similarly, another study in Northwestern Nigeria which assessed the prevalence of sexual violence presentation at a tertiary health facility found that about a third of the female children presenting were street hawkers (Ashimi et al., 2015). Perpetrators of these acts included strangers and some people known to the victims. Sexually abused children suffer physical and mental consequences. They are also at risk of drug addiction, early and unwanted pregnancy, HIV and other 
sexually transmitted diseases (UNICEF,1997).

The long hours spent on the street and in traffic also expose hawkers to street dust which contains high levels of polycyclic aromatic hydrocarbons (PAH) from vehicle exhaust effluents. The exposure to $\mathrm{PAH}$ and its derivatives could increase their lifetime risk of cancer (Obiri et al., 2013). Children are more vulnerable and susceptible than adults biologically. Absorption of toxin through the skin and lungs are higher than in adults (Surendra and Gowri, 2009). Children have also been reported to be more susceptible to noise, heat and ionizing radiations (CHSICL,1998).

Different studies have reported numerous health conditions among children hawking in different parts of the country (Ikechebelu et al., 2008; Sherman,1992). This study set out to identify the health problems if any of child hawkers in Uyo, Akwa Ibom State with the intention of making useful recommendations to government and parents based on the findings.

\section{METHODOLOGY}

This was a cross-sectional descriptive study carried out in April, 2015 in Uyo, the capital of Akwa Ibom State. Uyo has an estimated population of 304,000 (NPC, 2006). The study population consisted of children between the ages of 5 to 17 years engaged in street hawking within the State capital. They generally tend to hawk their goods along the streets but tend to be more concentrated around traffic light intersections within the city. All major traffic light points within Uyo metropolis where child street hawkers are commonly found were included in the study.

A total of 230 children were interviewed which was the sample size calculated based on the prevalence of child street hawkers involved in road traffic accident, $(16 \%)$, from a previous Nigerian study (Dada, 2013) and an adjustment of $10 \%$ for non response with a $95 \% \mathrm{Cl}$ and $5 \%$ precision. An interviewer-administered semistructured questionnaire was used for data collection. It was administered in English and vernacular by 4 trained research assistants. Data was collected from all consenting child street hawkers found at the study locations consecutively over 4 days of data collection until the required sample size was attained. Only responses from 225 children were used for the final data analysis.

The data was entered and analyzed using SPSS statistical software version 20. Data analysis was done using descriptive statistics (Frequency, proportions, means and standard deviation to summarize variables) and Inferential statistics (chi square, to test the significance of association between two categorical variables) with level of significance set at $5 \%$.

Permission to carry out the research was obtained from Ethical Committee of Akwa Ibom State Ministry of health. All study participants gave verbal consent and willingly participated in the study. They were neither forced nor cajoled and were given the opportunity of discontinuing their participation at any point during the interview for data collection.

\section{RESULTS}

A total of 225 hawkers participated in the study, with a male: female ratio of 1.2:1. Eighty eight (39.1\%) respondents worked all day. Most, 201 (89.3\%) worked for 4-7 days weekly. Up to $54(24.0 \%)$ spent $9-13$ hours daily on the streets (Table 1).

Data on hazard indicators showed that about 135 $(58.5 \%)$ of them perceived street hawking as dangerous, out of which $64(28.6 \%)$ perceived it as being very dangerous. During the course of their trading, 69(30.7\%) of the respondents had been involved in road traffic accidents. Significantly more females $33(31.1 \%)$ than males $10(8.4 \%)$ reported ever experiencing sexual harassment or rape $(p<0.001)$ (Table 2$)$.

The perception of risk as very dangerous seemed to increase with age from $7.7 \%$ among those aged 5-9 years to $33.8 \%$ among those aged 15 years and above. The difference was however not significant (Table 3).

Headaches, 46 (20.4\%), general body pains, 40 $(17.7 \%)$ and leg pains, $36(16.0 \%)$ were the top three most frequently experienced health problems among the respondents. One case of pregnancy was reported. (Table 4)

\section{DISCUSSION}

This study was carried out to determine the health problems of hawkers aged 5-17 years in Uyo metropolis in southern Nigeria. Both male and female children were involved in street trading. Parents often send their children to hawk probably due to the families' need to make extra income. This however exposes the children to numerous risks, many of which may affect their health. This risk is further increased by the period of exposure to hazardous conditions. Over one third of the children in this study reported working all day, some everyday of the week. Okafor estimated that over 4 million Nigerian children work for an average of 12 hours daily (Okafor, 2010).

More than $50 \%$ of the hawkers in the present study perceived street hawking as dangerous. During the course of their trading, almost a third of them had been involved in road traffic accident. The hawkers often have to run after customers in moving vehicles to sell their items of trade or collect money for already sold items. This sometimes involves crossing the road without looking, thus putting them at risk of being knocked down by moving vehicles especially when the traffic lights permit the vehicles to move. A study by Shailong 
106 J. Med. Med. Sci.

Table 1: Work characteristics of hawkers $(n=225)$

\begin{tabular}{lc}
\hline Variables & $\mathbf{N}(\mathbf{n} \%)$ \\
\hline Work period & \\
Morning only & $28(12.4)$ \\
Afternoon only & $37(16.4)$ \\
Evening only & $72(32.0)$ \\
All day & $88(39.1)$ \\
Number of days worked/week & \\
1-3 days & $24(10.7)$ \\
$4-7$ days & $201(89.3)$ \\
Mean (sd) & $5.43(1.277)$ \\
Range & $2-7$ days \\
Daily hours worked/day & \\
$0-4$ hrs & $65(28.9)$ \\
$5-8$ hrs & $106(47.1)$ \\
$9-13$ hrs & $54(24.0)$ \\
Mean (sd) & $6.52(2.641)$ \\
Range & $2-13$ Hours \\
\hline
\end{tabular}

Table 2: Hazard indicators disaggregated by sex

\begin{tabular}{|c|c|c|c|c|}
\hline & Male $(n=119)$ & Female $(n=106)$ & Total $(n=225)$ & Statistical indices \\
\hline \multicolumn{5}{|l|}{ Perception of risk $n=224$} \\
\hline Not dangerous & 49 (41.5) & $40(37.7)$ & 89 (39.7) & $x^{2}=0.684$ \\
\hline \multirow{2}{*}{$\begin{array}{l}\text { Slightly dangerous very } \\
\text { dangerous }\end{array}$} & $38(32.2)$ & $33(31.1)$ & $71(31.7)$ & $p=0.710$ \\
\hline & $31(26.3)$ & $33(31.1)$ & $64(28.6)$ & \\
\hline \multicolumn{5}{|l|}{ Ever had an rta } \\
\hline Yes & $37(31.1)$ & $32(30.2)$ & $69(30.7)$ & $x^{2}=0.022$ \\
\hline No & $82(68.9)$ & $74(69.8)$ & $156(69.3)$ & $p=0.883$ \\
\hline \multicolumn{5}{|c|}{$\begin{array}{l}\text { Ever been sexually harassed } \\
\text { or raped }\end{array}$} \\
\hline Yes & $10(8.4)$ & $33(31.1)$ & $43(19.1)$ & $x^{2}=18.735$ \\
\hline No & $109(91.6)$ & $73(68.9)$ & $182(80.9)$ & $\hat{p}=<0.001^{*}$ \\
\hline
\end{tabular}

*Statistically significant

Table 3: Relationship between age of children and risk perception

\begin{tabular}{|c|c|c|c|c|}
\hline & \multicolumn{3}{|c|}{ Age of children in years $n=224$} & \multirow{2}{*}{$\begin{array}{l}\text { Statistical } \\
\text { indices }\end{array}$} \\
\hline & $\begin{array}{c}5-9 y r s(n=13) \\
n \%\end{array}$ & $\begin{array}{c}10-14 y r s \\
(n=137) n \%\end{array}$ & $\begin{array}{c}\text { 15yrs \& above } \\
(n=74) n \%\end{array}$ & \\
\hline Perception of risk & & & & \\
\hline Not dangerous & $7(53.8)$ & $53(38.7)$ & $29(39.2)$ & \\
\hline Slightly dangerous & $5(38.5)$ & $46(33.6)$ & $20(27.0)$ & $x^{2}=4.265$ \\
\hline Very dangerous & $1(7.7)$ & $38(27.7)$ & $25(33.8)$ & $p=0.371$ \\
\hline
\end{tabular}

reported that $84 \%$ of the child hawkers had actually been knocked down by motorists (Shailong et al., 2011).
Similar findings have been reported in other studies (Ayodele and Olubayo-Fatiregun, 2014; Okafor, 2010). 
Johnson and Ihesie 107

Table 4: Health problems among hawkers

\begin{tabular}{lc}
\hline Health problems (multiple responses) & Frequency (\%) \\
\hline General body pains & $40(17.7)$ \\
Leg pains & $36(16.0)$ \\
Neck pains & $13(5.7)$ \\
Waist pains & $16(7.1)$ \\
Headaches & $46(20.4)$ \\
Sunburns & $26(11.6)$ \\
Tiredness/weakness & $34(15.1)$ \\
Fever & $24(10.6)$ \\
Chest pains & $2(0.8)$ \\
Cough & $2(0.8)$ \\
Rashes & $31(13.8)$ \\
Pregnancy & $1(0.4)$ \\
Hand pains & $2(0.8)$ \\
Stomach pains & $2(0.8)$ \\
Nil & $36(16.0)$ \\
\hline
\end{tabular}

One of the hazards child hawkers experience is becoming sexually active prematurely. About a third of the female hawkers in this study reported experiencing sexual harassment or rape, thus exposing them to the risk of numerous health conditions such as sexually transmitted infection, including HIV. They could also have acquired unwanted pregnancies, with the attendant risks, including vesico vaginal fistula (VVF), considering their poorly developed reproductive organs. Others may even lose their lives in the course of attempting to get rid of the pregnancy through abortion. One case of teenage pregnancy was reported in the present study. A study carried out by Osinowo reported that $15.4 \%$ of the female adolescent hawkers studied had committed induced abortion at least twice and had been pregnant without knowing who was responsible, had experienced and suffered rape and also contacted sexually transmitted diseases (Osinowo, 1996). The prevalence of sexual harassment was significantly higher among girls than boys in this study as less than a tenth of the boys reported such incidence. Similar findings were reported in a study carried out in Ibadan where $54.5 \%$ of the girls reported having lost their virginity compared to $37 \%$ of the boys (Abisoye, 2013). Ikechebelu et al in their study among female hawkers with a mean age of 13 years also reported that $130(69.9 \%)$ had been sexually abused with $32(17.2 \%)$ having had penetrative sexual intercourse, some being forced and more submitting willingly while hawking. About $60 \%$ of the sexual partners in that study were adults (Ikechebelu, 2008). Hawking thus exposes the children to adults who could lure them by pretending to want to buy their goods or offering money or food to the hungry and tired children and consequently taking advantage of them. The practice thrives because after such an event, many of the girls fear being stigmatized and therefore do not report (Fawole et al, 2004).

Over $80 \%$ of respondents reported experiencing different health conditions since they commenced hawking. These included headache, musculoskeletal pains in different parts of the body, sunburns, fever and weakness. These children undergo long hours of trekking covering far distances, often with no food or rest. Other studies have also reported exposure to extremes of weather, insects and reptile bites, hunger and deprivation which can result in different health conditions including respiratory tract infection, malnutrition, mental illness and substance abuse (Ikechebelu et al., 2008; Sherman, 1992). Malnutrition was reported to be significantly more prevalent among working children compared to non working children in a study carried out in Ibadan, Nigeria (Omokhodion and Omokhodion, 2004).

Moreover, children engaged in trading even when not on the streets have been reported to also experience numerous health challenges. In a study among children who sold in a market in Ibadan, $28 \%$ reported injuries, $12 \%$ skin infections, $21 \%$ fever, $19 \%$ musculoskeletal problems and $15 \%$ URTI. Thirty six percent were also underweight (Omokhodion and Omokhodion, 2001). The children spend most of their day selling different items and may have no decent meal until they return home in the evening and many may become malnourished. This in turn lowers their immunity and makes them more prone to different infections. A clear relationship between malnutrition, impaired immunity and infection has been documented (Hughes and Kelly).

Also, these illnesses often necessitate purchases of drugs which further deplete the family's meager resources, tipping them further into poverty. 
The perception of hawking as a very dangerous trade by the street hawkers in this study seemed to increase with age. This implies that the older children were more likely to apply more caution while trading than the younger ones who are more naïve by reason of their ages. Risk taking behavior has been reported to be higher among the younger children (Surendra and Gowri, 2009).

\section{CONCLUSION}

The young hawkers were exposed to numerous health problems in this study, some of which could be life threatening. This spanned from RTA to teenage pregnancy. Awareness campaigns should be carried out in all media outfits to discourage the parents from exposing their children to such health problems. Government should enforce the laws that prohibit street hawking by children and also provide free education for the children in order to encourage the parents to send their children to school.

\section{REFERENCES}

Abisoye AO (2013). The prevalence of child hawkers in motor parks in Ibadan Municipality: an overview. OJSSR. 1(7):174-179

Ashimi A, Amole T, Ugwa E (2015). Reported Sexual Violence among Women and Children Seen at the Gynecological Emergency Unit of a Rural Tertiary Health Facility, Northwest Nigeria. Ann. Med. Health Sci. Res. 5(1): 26-29.

Ayodele RB, Olubayo-Fatiregun (2014). Accidental injuries among juvenile hawkers: Clog in the Wheel of Sustainable Socio-Economic Development of a Nation. Asian J. Hum. Soc. Sci. 2 (2): 19-30

Committee on the Health and Safety Implications of Child Labour (CHSICL) (1998). Protecting Youth at Work: Health ,Safety and Development of Working Children and Adolescents in the United States, Washington DC: National Academy Press..

Dada O (2013). A Sociological Investigation of the Determinant Factors and the Effects of Child Street Hawking in Nigeria: Agege, Lagos State, Under Survey. Int. J. Asian Soc. Sci. 3:114-137.

Fawole OI, Ajuwon AJ, Osungbade KO (2004). Violence and HIVIAIDS prevention. Afr. J. Med. Sci. 33(4):347-353
Gali BM, Madziga AG, Naaya HU (2004). Epidemiology of childhood burns in Maiduguri north eastern Nigeria. Niger. J. Med.13(2):144-7

Hughes S, Kelly P (2006). Interactions of malnutrition and immune impairment, with specific reference to immunity against parasites. Parasie Immunol. 28(11): 577-588

Ikechebelu JI, Udigwe GO, Ezechukwu CC, Ndinechi AG, JoeIkechebelu NN (2008). Sexual abuse among juvenile street hawkers in Anambra State, Nigeria. AJRH. 12 (1):111-119.

ILO (2015). ILO Conventions and Recommendations on child labour. Geneva, Switzerland: International Labour Organization [cited 2015 April 29]. Available from: http://www.ilo .org/ipec/facts/lLO conven tionsonchildlabour/lang--en/index.htm.

ILO (2013). International Programme on the Elimination of Child Labour (IPEC) (2012). Hazardous child labour. ILO Global estimates (2013).

National Population Commission (NPC) (2006). Census figures 2006.

Obiri S,Cobbina SJ, Armah FA,Luginaah I (2013). Assessment of cancer and non-cancer health risks from exposure to $\mathrm{PAH}$ in street dust in the Tamale metropolis, Ghana. J. Environ. Sci. Health. (48):408-16

Okafor EE (2010). Child labour dynamics and implication for sustainable development in Nigeria. J. Sustain. Dev. Afr. 12(5): 8-17.

Omokhodion FO (2001) Omokhodion SI. Health problems and other characteristics of child workers in a market in Ibadan. Afr. J. Med. Med. Sci. 30(1-2): 81-85

Omokhodion FO (2004). Omokhodion SI. Health status of working and non working children in Ibadan, Nigeria. Ann. Trop. Paediatr. 24 (2): $175-178$

Osinowo AO (1996). Street Children and Psychomedical Consequences. Afr. J. Med. 2: 24

Shailong CN, Onuk EG, Beshi BA (2011). Socio-economic factors affecting child hawkers in Lafia Local Government Area, Nasarawa State PAT;7 (1) 64-73

Sherman DJ (1992). The Neglected health needs of street youth. Public Health Rep .107(4): 433-440

Surendra KY, Gowri S (2009). Environmental and Occupational Health Problems of Child Labour: Some Issues and Challenges for Future. J. Hum. Ecol. 28(2): 143-148

UNICEF (1997). The State of the Worlds' Children 1997. Oxford: Oxford University Press. 